\title{
ANALISIS KETRANSITIFAN DALAM “ROOTS OF THE NORTH MALUKU CONFLICT” DI JAKARTA POST (1999): ANALISIS WACANA KRITIS
}

\author{
Sunaidin ode mulae ${ }^{1}$ dan Sutiono Mahdi ${ }^{2}$ \\ ${ }^{1}$ Fakultas Sastra dan Budaya Universitas Khairun Ternate \\ ${ }^{2}$ Fakultas Ilmu Budaya Universitas Padjadjaran \\ Email:madiyahi.mu1481@gmail.com
}

\begin{abstract}
ABSTRAK. Studi analisis wacana kritis diterapkan untuk menganalisis isu-isu ideologi, dominasi, kekuasaan dan strategi teks berita. Studi ini mengambil objek Analisis Ketransitifan dalam "Roots of the North Maluku Conflict" di Jakarta post (1999), yang dikaji dengan pendekatan analisis kritis. Pendekatan ini memusatkan perhatian untuk melihat kenyataan di balik sebuah teks berita, kemudian dihubungkan ke tatabahasa fungsional untuk mengidentifikasi proses bahasa dan fungsi bahasa. Pendekatan itu untuk memahami dan memandang penggunaan bahasa dalam tuturan dan tulisan sebagai bentuk praktek sosial. Masalah yang diangkat ialah bagaimana proses material dalam teks berita dan bagaimana bentuk praktek wacana dalam berita. Metode yang digunakan di penelitian ini adalah metode analisis isi kualitatif. Metode ini digunakan untuk memahami pesan simbolik dari wacana teks, dalam hal ini teks-teks berita. Sumber data yang digunakan dalam penelitian adalah berita konflik Maluku Utara (1999) di Jakarta Post yang terdiri 40 klausa, 13 paragraf, 602 kosakata. Hasil Penelitian menunjukan proses ktransitifan terdapat 6 proses material. Bentuk praktek wacana yang digunakan di dalam teks berita ialah praktek identifikasi dan kategorisasi. Dua bentuk itu dapat menunjukan posisi konflik di Maluku Utara (1999) sebagai konflik tapal batas yang bermuara pada konflik agama anatare Kristen dan Islam.
\end{abstract}

Kata Kunci: Proses Material, Analisis Wacana Kritis, Konflik Maluku Utara.

\section{TRANSITIVITY ANALYSIS IN "ROOT OF THE NORTH MALUKU CONFLICT" IN THE JAKARTA POST (1999): CRITICAL DISCOURSE ANALYSIS}

ABSTRACT. Study on Critical Discourse Analysis is often applied to analyzed issues of ideology, domination, power and strategy in news text. The object of this study is transitivity analysis in "Roots of the North Maluku Conflict" in the Jakarta Post (1999), which was studied by the critical analysis approaches. The central of this approach is studied to see the reality in the news text, and then it is conected to function grammar for identification the process and function of language. That aprroach to undertand and viewed the use of language in oral and write as form social practice. The problem raised is how the material process in news text and how on form discourse practice in news. The mothed employed for this research is the qualitative size approach. This approach is used for understanding symbolic of messages from text practice, in this case is news texts. The data of source is used in this research, namely the conflict news in north Maluku (1999) in the Jakarta Post consist of 40 clauses, 13 paragrahp, and 602 vocabularies. The result of study showed the transitivity process consists of 6 material processes. Discourse practice form is used in news text are identivication practice and categorization. The two forms can be showed of the conflict position in north Maluku (1999) is conflict of land limit until that the effect to relagion conflict between Christiany and Moslim.

Key words: Material process, Critical Discourse Analysis, North Maluku Conflict.

\section{PENDAHULUAN}

Peneliti mengawali latar belakang penelitian ini dengan mendeskripsikan secara umum tentang landasan yuridis tentang Maluku Utara dan masyarakatnya. Provinsi Maluku Utara terpisah dari provinsi Maluku di Ambon tertuang dalam UU RI nomor 46 Tahun 1999. Kemudian, diterbitkannya PP 42 tahun 1999 tentang pembentukan dan penataan beberapa kecamatan di wilayah kabupaten daerah tingkat II Maluku Utara dalam wilayah propinsi daerah tingkat I Maluku. Sejak diundangkan dan diberlakukannya PP 42/1999 tertanggal 26 Mei 1999 sampai dengan Agustus 1999 oleh Presiden RI Bacharuddin Jusuf Habibie, dan diundangkan di Jakarta oleh Menteri Negara Sekretaris Negara RI Prof. Dr. H. Muladi, S.H. PP 42/1999 pasal 1 huruf (a) adalah akar konflik di Maluku Utara yakni membentuk kecamatan Makian Malifut di wilayah tanah adat masyarakat Kao suku asli Halmahera Utara. Pembentukan kecamatan Makian Malifut itu diperkuat pada mukadimah PP 42/1999 yakni "bahwa untuk mengantisipasi akibat bahaya Gunung Kie besi di Pulau Makian Kabupaten Daerah Tingkat II Maluku Utara dalam wilayah Propinsi Daerah Tingkat I Maluku, dan agar terselenggaranya pelaksanaan tugas-tugas pelayanan di bidang pemerintahan dan pembangunan serta untuk meningkatkan pelayanan terhadap masyarakat, dipandang perlu membentuk kecamatan Makian Malifut dan menata kecamatan Kao dan Kecamatan Jailolo di wilayah Kabupaten Daerah Tingkat II Maluku Utara, Propinsi Daerah Tingkat I Maluku". (Pasal 1 huruf (a) PP 42/1999)1.

Dengan diberlakukannya PP 42/1999 ini, munculkan isu politik lokal yang sangat kuat di daerah. Padahal, kurang lebih 24 tahun mengungsinya suku Makian dari pulau Makian (1975-1999) ke wilayah adat masyarakat Kao di Halmahera bagian Utara tidak pernah mengalami kerusuhan atau

1. Republik Indonesia, Peraturan Pemerintah Nomor 42 Tahun 1999,(Pasal 1 huruf (a)), hlm.1. 
pertikaian antara etnis maupun agama atau tapal batas. Namun, sejak diberlakukannya PP 42/1999 oleh Pemerintah Pusat di Jakarta kurang lebih empat bulan (26 Mei 1999 - Agustus 1999), konflik pertama kali pecah terjadi antar masyarakat dua etnis yakni Makian Malifut dan masyarakat adat Kao. Konflik itu mempersoalkan batas- batas wilayah dan nama kecamatan. Konflik berujung pada syara atau konflik agama di Maluku Utara sejak bulan Agustus 1999, karena secara bersamaan konflik di Ambon tahun 1999 memuncak. Sampai dengan penelitian ini dilaksanakan PP 42/1999 masih menyimpan masalah yakni masih terdapat sejumlah Desa dan batasbatasnya menjadi persengketaan di dua kabupaten yakni kabupaten Halmahera Utara di Tobelo dan Kabupaten Halmahera Barat di Jailolo.

Dengan wacana PP 42/1999 menjadi suatu masalah di mana peneliti mencoba untuk mengungkap dan memposisikan permasalahan itu dengan analisis wacana kritis. Sebagaimana dalam analisis wacana kritis kata, "wacana" banyak digunakan oleh berbagai disiplin ilmu pengetahuan mulai dari ilmu bahasa, psikologi, sosiologi, politik, komunikasi, sastra dan lain sebagainya.

Penerapan konsep wacana dengan pengertian yang paling abstrak bahwa wacana mengacu pada penggunaan bahasa sebagai praktik sosial. Wacana bersifat konstitutif dan tersusun yang dapat dipahami sebagai jenis bahasa dalam suatu bidang khusus seperti wacana politik atau wacana konflik, sedangkan penerapan konsep wacana dengan penggunaan yang paling kongkrit adalah wacana sebagai suatu kata benda yang bisa dihitung mengacu pada cara bertutur yang memberikan makna berasal dari pengalaman atau perspektif tertentu (Fairclough,1993 dalam Michael Mayer. et.al (2000) $)^{2}$. Dalam hal ini, Fairclough memberikan batasan istilah wacana pada sistem semiotik seperti bahasa dan pencitraan yang cenderung membahas identitas sosial, hubungan sosial, sistem pengetahuan dan makna.

Pada konteks ini surat kabar bukan saja menjadi sudut perhatian dari ilmu komunikasi melainkan juga dapat menjadi kajian kebahasaan. Masih menurut pendapat Fairclough (1995) $)^{3}$ bahwa analisis wacana kritis menggunakan tiga aspek yang berbeda. Pertama, analisis teks (text analysis). Kedua, analisis proses produksi (interpretation process analysis). Ketiga, analisis sosiokultural (explanation sociocultural analysis). Dari ketiga aspek itu analisis teks memiliki pemahaman abstrak, yang merujuk pada penggunaan bahasa sebagai praktik sosial. Dalam hal ini paling penting di dalam pendekatan analisis wacana kritis adalah sifatnya yang holistik dan kontekstual. Hal tersebut sepaham dengan pendapat yang dikemukakan oleh Eriyanto $(2008)^{4}$, bahwa kualitas suatu analisis wacana kritis akan selalu dinilai dari

2. Stefan Titscher. et.al, Methods of Text and Discourse Analysis (London:Sage Publications,2000),hlm. 242

3 Norman Fairclough, Media Discourse, (Edward Arnold: United Kingdom, 1995), hlm. 140

4 Eriyanto, Analisi Wacana, pengantar Analisis Teks Media (Yogyakarta: LKIS, 2008), hlm. 104. segi kemampuannya untuk menempatkan teks dalam konteksnya yang utuh, holistik, melalui pertautan antara analisis pada jenjang yang lebih tinggi.

Dengan aspek dan sifat analisis wacana kritis tersebut, pendekatan analisis wacana kritis yang digunakan tidak hanya dapat dilakukan dengan analisis teks (teks analysis) terhadap posisi suatu media massa. Namun perlu dihubungkan pada konteks realitas sosial suatu masyarakat. Wacana konflik Maluku Utara di media Jakarta Post tahun 1999 adalah bagian dari praktek wacana. Praktik wacana yang digunakan media Jakarta Post adalah memproduksi dan menerbitkan berita selalu menggunakan bahasa Inggris. Menjadi menarik untuk peneliti agar ditelaah isi berita berbahasa Inggris di dalam media itu karena memberitakan tentang sejarah munculnya kerajaan-kerajaan di Maluku Utara yang kemudian dihubungkan dengan konflik yang bernuansa syara pada tahun 1999. Dengan merujuk pada permasalahan dan penjelesan yang dikemukakan di atas dapat dirumuskan dua pokok permasalah penelitian sebagai berikut: Pertama, Bagaimana proses material teks dalam berita " roots of the north Maluku conflict" di Jakarta post?. Kedua, Bagaimana bentuk praktik wacana teks dalam berita "roots of the north Maluku conflict" di Jakarta Post? Untuk mendiskusikan dua pokok permasalahan yang menjadi fokus penelitian. Peneliti akan menggunakan konsep analisis wacana kritis dan konsep proses sistem transitifitas.

Konsep Analisis wacana kritis mempunyai salah satu kekuatan untuk melihat dan membongkar politik ideologi di dalam media. Bahwa penting karena di dalam wacana yang bersifat kritis diyakini teks merupakan bentuk dari praktek ideologi atau pencerminan ideologi tertentu. Dalam hal ini sejalan dengan pendapat bahwa praktek ideologi merupakan tanda yang hadir melalui sirkulasi ide dan representasi realitas sosial (Richardson (2007) . Adapun konsep ideologi itu mempunyai hubungan dengan teks yang diterjemahkan ke dalam konteks. Ini sejalan dengan pendapat Hatim (2004:102) dalam Heriyanto $(2011)^{6}$ yakni "the tacit assumption, beliefs and value systems which are shared collectively by social groups".

Ideologi itu bisa diketahui secara transparan sistem ketransitifan perlu dikemukakan sehingga teks mudah diketahui melalui prosesnya. Setaip teks berita tentunya menggunakan bahasa dan setiap teks bahasa mempunyai fungsi. Salah satu fungsi bahasa adalah fungsi ideosional yang dikemukakan oleh Halliday $(2004: 332)^{7}$ yakni sebagai fungsi bahasa baik penutur maupun penulis terkait dengan pengalamannya

\footnotetext{
5. John E,Richardson, Analysing Newspapers, An Approach From The British Library (New York:Palgrave Macmillan of St. Martin's Press),hlm.130.

6. Heriyanto,Pelangi Budaya (Bandung:UvUla Press FakultSastra UNPAD, 2011 ),hlm.127.

7 Halliday,M.A.K, and Matthiessen, An introduction to Fucntion Grammar,Thirth edition (London:Edward Arnol,2004),hlm.332
} 
dan berhubungan dengan fenomena nyata di dunia, dan juga termasuk pengalaman internal dalam alam sadarnya, reaksinya, pemahaman, dan persepsi, disamping tindakan linguistik dalam berbicara dan memahami. Fungsi ideosional pada umumnya direpresentasikan oleh sistem ketransitifan dalam tata bahasa.

\section{METODE}

Bahwa untuk menjawab masalah dan mencapai tujuan penelitian sebagaimana telah dirumuskan, metode penelitian yang digunakan adalah analisis isi kualitatif yaitu suatu metode yang bisa digunakan untuk memahami pesan simbolik dari suatu wacana atau teks berita. Dalam penelitian ini yang di maksud dengan pesan simbolik tersebut adalah aspek-aspek sosial, politik, ideologi dan konflik yang terdapat di dalam wacana berita, sedangkan yang dimaksud dengan konteks ialah aspek historis, sosial, budaya, ekonomi, politik, etnik, dan konflik yang memengaruhi terbentuknya wacana.

Penelitian ini bersifat mendeskripsikan teks berita secara kritis. Pendekatan analisis yang digunakan ialah pendekatan kritis yakni pendekatan yang memusatkan perhatian terhadap pembongkaran aspek-aspek yang tersembunyi di balik sebuah kenyataan yang tampak (virtual reality), untuk itu digunakan kerangka analisis wacana kritis dari Fairclough, yakni kerangka analisis untuk memperoleh pemahaman teks secara utuh, analisisnya harus diletakan dalam sebuah konteks sosial kultural dan latar belakang pembuat teks.

Kerangka analisis tersebut dipilih karena peneliti berusaha menutupi kekurangan analisis isi yang hanya menekankan pada pesan yang tampak, kurang memerhatikan konteks dan mengabaikan makna simbolis pesan, sedangkan untuk mempertajam analisis membongkar pesan dalam teks berita, peneliti menghubungkan sudut pandang tata bahasa fungsional, sebagai fungsi bahasa baik penutur maupun penulis terkait dengan pengalamannya dan berhubungan dengan fenomena nyata di dunia, dan juga termasuk pengalaman internal dalam alam sadarnya, reaksinya, pemahaman, dan persepsi, disamping tindakan linguistik dalam berbicara dan memahami, Halliday $(2004: 332)^{8}$.

Berdasarkan sifat dan fokus penelitian yang dilakukan, peneliti menggunakan sumber data dari online di website Jakarta post www.thejakartapost. $\underline{\text { com }}^{9}$ yakni hanya satu berita berbahasa Inggris dengan judul "Roots of the North Maluku conflict" terdiri 602 kata, 13 paragraf dan 40 klausa. Media online Jakarta Post dipilih untuk menjadi objek penelitian karena jenis teks yang digunakan secara luas adalah berbahasa Inggris, tentunya banyak pembaca dari dalam negeri maupun luar negeri yang meminati untuk membacanya baik secara nasional maupun internasional.

8. Halliday,M.A.K, and Matthiessen, An introduction to Fucntion Grammar,Thirth edition (London:Edward Arnol,2004),hlm.332-333.

9 http://www.thejakartapost.com/news/2000/01/25/ roots-north-maluku-conflict.html.

\section{HASIL DAN PEMBAHASAN}

Peneliti merujuk pada pendapat Halliday dan Mathiessen $(2004)^{10}$ bahwa proses ketransitifan terbagi dalam enam proses yaitu (1) Proses material (Material process), (2) Proses Mental (Mental process), (3) Proses Behavioral (Behavioral process), (4) Proses verba (Verbal process), (5) Proses relasional (Relational process), (6) Proses ekistensial (Existential process). Dari enam bentuk proses ketransitifan tersebut peneliti hanya menganalisis proses material.

\section{Proses Material}

Proses material merupakan proses kata kerja yang melukiskan atau menggambarkan proses tindakan fisik, seperti penggunaan kata kerja eat, go, given, dan sebagainya. Dalam hal ini, ada dua atau lebih peran partisipan dalam proses material yang mempunyai hubungan pada proses ke suatu pelaku yang disebut dengan istilah partisipan Actor dan Goal. Partisipan Actor dikenal sebagai suatu subjek logika (logical subject).

Partisipan Goal adalah bertindak sebagai suatu logika objek langsung (logica direct object). Pada umumnya, partisipan Goal biasanya suatu kata benda atau suatu kata ganti seseorang. Menurut Halliday \& Matthiessen (2004) ${ }^{11}$, Proses material adalah tindakan-tindakan fisik dalam kehidupan nyata di dalam dunia ini. Partisipan dalam proses material pada umumnya terdiri dari partisipan Actor, partisipan Goal, Partisipan Scope, partisipan Attribute, partisipan Client, dan partisipan Recipient. Partisipan-partisipan itu mempunyai fungsi masingmasing: partisipan Actor mempunyai fungsi yakni seseorang atau kelompok yang melakukan suatu tindakan.

Partisipan Goal berfungsi seseorang atau kelompok yang dipengaruhi oleh suatu tindakan. Partisipan Scope berfungsi sebagai partisipan yang seseorang atau kelompok tidak dipengaruhi oleh suatu tindakan. Partisipan Attribute berfungsi menghubungkan sesuatu yang sebenarnya. Partisipan Client berfungsi sebagai partisipan untuk seseorang atau kelompok melakukan suatu tindakan, dan partisipan Recipient berfungsi untuk seseorang atau kelompok yang menerima sesuatu. Berdasarkan isi berita data (1) di dalam teks berita "roots of the north maluku conflict" di Jakarta post. Isi berita secara umum dapat dikemukakan bahwa wacana berita jelas terlihat mengalami proses material. Isi berita menunjukan aktifitas tindakan kekerasan pembunuhan masyarakat sipil di Maluku Utara secara penuh di redam oleh pemerintah melalui meliter. Actor dalam peristiwa itu dilakukan oleh masyarakat sipil. Tindakan masyarakat sipil atau aktor itu sangat jelas tergambar dalam klausa "the mass civiling killings

10. Halliday,M.A.K, and Matthiessen, An introduction to Fucntion Grammar,Thirth edition (London:Edward Arnol,2004),hlm.197.

11. Halliday,M.A.K, and Matthiessen, An introduction to Fucntion Grammar,Thirth edition (London:Edward Arnol,2004),hlm.197. 
in north maluku". Dengan demikian motif peristiwa kekerasan dalam bentuk pembunuhan masarakat sipil di Maluku Utara dapat dibongkar dengan analisis proses material sebagai berikut:

Data (1)

The mass civiling killings in north Maluku (Actor) have begun (Material Process) to subside with the increasingly force (Attribute) taken (Material process) by the goverment through the military (Goal) . (Pragraph 1).

Tabel 1. Analisis Proses material data (1).

\begin{tabular}{lll}
\hline The mass havebegun & to subsidewith taken & bythe \\
civiling & the & goverment \\
killingsin & increasingly & through the \\
north & force & military \\
Maluku & &
\end{tabular}

Pt:Actor Pr:Material Pt:Attribute Pr:Material Pt:Goal

Dari penampangan tersebut, tergambar posisi masyarakat sipil adalah sebagai korban konflik, ditampilkan di dalam teks dengan apa adanya. Bahkan cenderung diadvokasi oleh yang memarjinalkan posisi masarakat sipil, yaitu adanya identifikasi dari redaksi Jakarta Post berupa penjelasan seperti pada kalimat "to subside with the increasingly force by the government through the military" di atas. Konflik masyarakat sipil hanya dideskripsikan di wilayah Maluku Utara secara umum. Kalau dicermati secara hati-hati konteks peristiwa. Tampaknya teks terdapat suatu dominasi kekuasaan yang menawarkan suatu ideologi tanpa sadar kepada pembaca.

Ideologi yang dimaksudkan kemungkinan besar strategi militer dan pemerintah berencana meredam konflik di Maluku Utara dengan cara menerapkan wajib militer. Apalagi, nominalisasi korban dalam teks di selipkan dalam isi berita. Sehingga memunculkan persepsi sesungguhnya konflik di maluku utara pada tahun 1999 itu sebenarnya konflik antar masyarkat sipil atau konflik agama ataukah konflik dengan pemerintah atau militer. Apalagi dalam teks tampak memunculkan kondisi sejarah Maluku Utara di masa lampau, dalam hal ini wacana konflik semakin di selipkan. Ini menunjukan ketakutan redaksi Jakarta Post dalam menulis konflik sesungguhnya di Maluku Utara pada tahun 1999. Dan apalagi pelaku kekerasan pembunuhan tidak dimasukan ke dalam teks karena keberadaanya tidak dapat dilacak oleh wartawan Jakarta Post.

Aktor lain yang seharusnya muncul di dalam teks ialah pemerintah dan militer yang akan meredam kekerasan pembunuhan justru aktor tersebut tidak ditampilkan karena adanya ketakutan struktural redaksi Jakarta Post. Motif redaksi Jakarta Post pada wacana di data (1) ialah menggambarkan apa adanya tentang kekerasan masyarakat sipil. Sikap ini lebih tampak pada data (2) yang mencoba memunculkan keberadaan sejarah kesultanan Ternate. Motif ini redaksi Jakarta Post cenderung mengaburkan dan menyembunyikan pelaku di dalam teks. Hal tersebut tampak pada kutipan teks di data (2) di bawah ini:
Data (2)

The history of the fierce resistance and rebellion of the people of northern Maluku (Actor) against external values is (Material process) inextricably bound to the development (Attribute), prosperity and, later, the deterioration of its sultanates (Goal). The sultanate dominion system in northern Maluku (Goal) emerged (Material process) in the 13th century (Circm:time) led by Sultan Cico a.k.a Masyur Malamo (1257-1277) (Actor). (Paragraph 2)

Tabel 2. Analisis Proses Material data (2)

\begin{tabular}{|c|c|c|}
\hline $\begin{array}{l}\text { The history of the fierce againstexternal } \\
\text { resistance and rebellionvalues is } \\
\text { ofthe people of northem } \\
\text { Maluku }\end{array}$ & $\begin{array}{l}\text { nextricably bound } \\
\text { to the development }\end{array}$ & $\begin{array}{l}\text { prosperity and, later, } \\
\text { the deterioration of its } \\
\text { sultanates }\end{array}$ \\
\hline Pr: Material & Pt:Attribute & Pt:Goal \\
\hline $\begin{array}{l}\text { The sultanate dominion emerged } \\
\text { system in northern } \\
\text { Maluku }\end{array}$ & $n$ the 13 th century & $\begin{array}{l}\text { led by Sultan Cico } \\
\text { a.k.a Masyur Malamo } \\
\text { (1257-1277) }\end{array}$ \\
\hline Pr: Material & Circm: Time & Pt:Actor \\
\hline
\end{tabular}

Dari analisis tabel 2, di atas dapat digambarkan bahwa proses material muncul dengan bentuk nominal group "against external values is" dan bentuk verba "emerged". Actor dan Goal hadir dua kali di kalimat adalah Penjelasan bahwa strategi wacana yang umum digunakan oleh redaksi Jakarta Post pada wacana berita di data (2) berhubungan dengan pendefinisian suatu kelompok sehingga peristiwa atau tindakan tertentu dapat mensugestikan makna tersirat. Dalam hal ini, praktek wacana yang dilakukan oleh redaksi Jakarta post memberikan penegasan makna pada publik bahwa kehadiran wacana kerajaan kesultanan Ternate di masa lalu adalah interpretasi dari kerajaan Islam yang selalu melakukan perlawanan melawan penjajah dan melawan nilai-nilai yang datang dari luar diri mereka.

Dalam konteks wacana itu jika diperhatikan terdapat makna multi tafsir dengan hadirnya klausa bebas "inextricably bound to the development" yang mempunyai tafsiran bahwa masyarakat kesultanan kemungkinan mengembangkan dominasinya untuk penyebaran agama di wilayah ekspansinya. Dalam hal ini, redaksi Jakarta Post menghadirkan perbedaan makna yang berarti bahwa masyarakat kesultanan selalu hidup lebih baik dari masyarakat yang bukan masyarakat kesultanan, ini dapat dilihat pada klausa "prosperity and, later, the deterioration of its sultanates", bahwa kemakmuran dan kemunduran, kemerosotan di kesultanan Ternate ditentukan sendiri oleh masyarakatnya yang sepahaman keimanan. Walaupun konteks yang ditunjukan oleh wartawan Jakarta Post terhadap teks berita itu, terdapat pemarjinalisasi aktor dalam teks atau tidak memunculkan tentang konflik masyarakat sipil. Namun secara aspek politik konflik selalu menguat sejak lama yakni sejak kerajaan Ternate melakukan perlawanan dengan bangsa penjajah yang notabene membawa misi kristenisasi di Maluku Utara. 
Dalam analisis data jelas terdeteksi dominasi kekuasaan yang dimunculkan, walaupun tidak dimunculkan oleh wartawan Jakarta Post. Pemandangan ini jelas terjadi marjinalisasi dalam isi berita, dimana terdapat suatu idelogi strategi teks yang ingin disampaikan bahwa dominasi kekuasaan kesultanan hadir cukup lama yakni pada tahun 1257-1277 adalah sumber dari kekerasan konflik pembunuhan masyarakat sipil di masa lalu dan berdampak di masa sekarang khususnya pada tahun 1999-2000. Konteks ini semakin dikaburkan situasi konfilk masyarakat sipil di Maluku Utara, seakan pencetus konflik adalah kesultanan Ternate. Ini juga sangat nampak terlihat pada diktum di data (3) dalam isi berita bahwa dominasi terkuat adalah kejayaan kerajaan Ternate dari beberapa kerajaan di Maluku Utara. Penjelasannya dapat dilukiskan sebagai berikut:

Data (3)

Within the first three centuries of its establishment (Scope), The Ternate Sultanate (Actor) ruled (material process) in northern Maluku (Goal). the other sultanates-Jailolo, Tidore and Bacan (Actor) existed (Material process) under the umrella of Ternate (Goal). (Paragraph 4).

\begin{tabular}{|c|c|c|}
\hline $\begin{array}{l}\text { The history of against } \\
\text { the fierce external values } \\
\text { resistance and is } \\
\text { rebellion of } \\
\text { the people of } \\
\text { northern } \\
\text { Maluku }\end{array}$ & $\begin{array}{l}\text { nextricably } \\
\text { bound to the } \\
\text { development }\end{array}$ & $\begin{array}{l}\text { prosperity } \\
\text { and, later, the } \\
\text { deterioration } \\
\text { ofits } \\
\text { sultanates }\end{array}$ \\
\hline$\overline{P t}$ : Actor $\quad$ Pr: Material & Pt: Attribute & Pt: Goal \\
\hline $\begin{array}{l}\text { The sultanate emerged } \\
\text { dominion } \\
\text { system in } \\
\text { northern } \\
\text { Maluku }\end{array}$ & $\begin{array}{l}n \text { the } 13 \text { th } \\
\text { century }\end{array}$ & $\begin{array}{l}\text { led by Sultan } \\
\text { Cico a.k.a } \\
\text { Masyur } \\
\text { Malamo } \\
\text { (1257-1277) }\end{array}$ \\
\hline Pr: Material & Circm: Time & Pt:Actor \\
\hline
\end{tabular}

Dalam analisis data di tabel (3), proses material merupakan proses yang menafsirkan kegiatan atau tindakan yang dilakukan oleh kesultanan Ternate kepada kesultanan lainnya di Maluku Utara. Proses material itu dimunculkan dengan kata "ruled" dan "existed". Partisipan Actor di munculkan dengan frasa "the Ternate sultanate" dan "the other sultanatesJailolo, Tidore and Bacan" adalah ekspresi dari dominasi kekuasaan kesultanan Ternate kepada kesultanan-kesultanan lainya di Maluku Utara seperti kesultanan Jailolo, Tidore dan Bacan.

Pemilihan kata-kata "the Ternate sultanate" dan "the other sultanates- Jailolo, Tidore and Bacan" merupakan strategi identifikasi oleh wartawan bahwa masyarakat sipil di Maluku Utara memiliki kemampuan untuk meredam konflik melalui pihak kesultanan Ternate, Jailolo, Tidore dan Bacan. Masyarakat sipil tidak merasa yakin jika pemerintah apalagi menggunakan militer dalam menyelesaikan konflik. Walaupun, di dalam teks wacana di data (3) tidak memunculkan kata - kata yang berbauh konflik. Namun, secara eksplisit dapat diungkap bahwa peran empat kesultanan di Maluku Utara sangat mampu membuat masyarakat Maluku Utara menyelesaikan konflik yang bernuansa syara pada 1999-2000.

Praktek wacana yang dihadirkan oleh wartawan Jakarta Post adalah menggunakan latar konsep sejarah dalam penyelesaian konflik di Maluku Utara. Redaksi Jakarta post sengaja menselipkan pemberitaan konflik kekerasan pembunuhan masyarakat sipil. Namun menghubungkan ke konteks kesejarahan dan kejayaan kesultanan di Maluku Utara. Motif ini redaksi Jakarta post mengindentifikasi kalau konflik masyarakat sipil di Maluku Utara disebabkan oleh terputusnya koordinasi antar kesultanan dengan pemerintah pusat dalam menetapkan suatu kebijakan. Dengan identifikasi seperti itu sikap kesultanan seakan-akan tersembunyi dalam teks.

Keberpihakan redaksi Jakarta post terhadap konflik dan pemarginalan tercermin pada kosakata yang digunakan "under the umrella of Ternate". Kata tersebut bermaksud "suatu kekuasaan di bawah pengaruh kerajaan atau kesultanan Ternate". Pilihan kata tersebut sangat eksplesit dan dapat menarik perhatian khalayak. Kalimat penjelas selanjutnya yang merupakan identifikasi redaksi Jakarta post yang cenderung memarginalkan posisi pemberitaan konflik di Maluku Utara, yakni sebagai berikut.

Data (4):

the nationalist struggle (Actor) againts domination of the west (Material process) which was (Material Process) an expression of patriotism (Scope), tied (Material Process) to Islamic allegiance and solidarity (Goal). (Paragraph 7)

Tabel 4. Analisis Proses material data (4)

\begin{tabular}{|c|c|c|}
\hline $\begin{array}{l}\text { the nationalist which was } \\
\text { struggle againts } \\
\text { domination of } \\
\text { the west }\end{array}$ & $\begin{array}{l}\text { an expression of Tied } \\
\text { patriotism, }\end{array}$ & $\begin{array}{l}\text { to Islamic } \\
\text { allegiance } \\
\text { and } \\
\text { solidarity }\end{array}$ \\
\hline
\end{tabular}

Pt: Actor Pr: Material Pt: Scope Pr: Material Pt:Goal

Berdasarkan analisis data (4) di atas proses material di perkenalkan dengan kosakata "which was" dan "tied". Pemilihan kata-kata itu menunjukan proses material memiliki kemampuan untuk menyakinkan kepada khalayak bahwa dominasi kesultanan Ternate pada abad ke-16 memasuki masa babak baru dalam usaha melakukan perlawanan kepada bangsa-bangsa barat seperti Spanyol dan Portugis.

Kehadiran bangsa Spanyol dan Portugis di Maluku Utara pada abad ke-16 telah mendominasi penguasaan sumber rempah-rempah seperti cengkih dan pala. Disamping penguasaan rempah-rempah bangsa Spanyol dan Portugis menjalankan misi kristenisasi dengan mendirikan sekolah Teologia kristen terbesar di Asia Tenggara yang berkedudukan di Ternate dan Tobelo kabupaten Halmahera Utara. Dari penjelasan di atas, tergambar bahwa kebejatan Bangsa Portugis dan Spanyol disembunyikan dalam teks. Sementara penderitaan yang dialami oleh masyarakat sipil Maluku Utara tidak muncul pada teks. Padahal, penderitaan yang dialami oleh masyarakat sipil Maluku Utara perlu ditampilkan agar menjadi pelajaran bagi khalayak.

Dalam hal ini, konteks dalam teks dideskripsikan 
oleh proses material Actor terhadap Goal adalah dominasi hegemoni dari bangsa Spanyol dan Protugis ke Maluku Utara. Strategi wacana yang mewarnai wacana data (4) ialah strategi wacana identifikasi. Beberapa teks yang berkaitan dengan identifikasi bangsa Portugis dan Spanyol terlukis sebagai berikut:

Data (5):

The portuguese (Actor) also set out to spread (Material process) Christianity through northen Maluku (Goal). The first theology school in Southeast Asia (Actor) was established (Material Process) in Ternate, inside the Santa Paolo fortress (Goal). The efforts involved coercion and violence (Circm:manner), with Portuguese missionaries (Recipeint) backed (Material Process) by full capacity armories (Actor). (Paragraph 8).

\begin{tabular}{|c|c|c|c|}
\hline $\begin{array}{l}\text { The also } \\
\text { portuguese }\end{array}$ & set out to spread & \multicolumn{2}{|c|}{$\begin{array}{l}\text { Christianity through northen } \\
\text { Maluku }\end{array}$} \\
\hline Pt: Actor & Pr: Material & \multicolumn{2}{|l|}{ Pt: Goal } \\
\hline $\begin{array}{l}\text { The first theology } \\
\text { school in Southeast } \\
\text { Asia }\end{array}$ & was established & \multicolumn{2}{|c|}{$\begin{array}{l}\text { in Ternate, inside the Santa } \\
\text { Paolo fortress }\end{array}$} \\
\hline Pt: Actor & Pr: Material & \multicolumn{2}{|l|}{ Pt: Goal } \\
\hline $\begin{array}{l}\text { The efforts } \\
\text { involved coercion } \\
\text { and violence }\end{array}$ & $\begin{array}{l}\text { with Portuguese } \\
\text { missionaries }\end{array}$ & Backed & $\begin{array}{l}\text { by full capacity } \\
\text { armories }\end{array}$ \\
\hline Circm:Manner & Pt: Recipient & Pr:material & Pt: Actor \\
\hline
\end{tabular}

Dalam tabel 5, data (5) di atas proses material dimunculkan dengan verba aktif "set out to spread" "was established", dan "backed". Verba aktif dihadirkan oleh redaksi Jakarta post dengan proses material untuk mengekspresikan tindakan dari suatu kelompok. Tindakan yang dimaksud adalah tindak nyata yang disembunyikan oleh wartawan pada teks berita. Pada klausa pertama tindakan nyata diekspresikan oleh Actor dengan frasa "the portuguese". Sedangkan Goal melukiskan kehadiran kelompok kristen di Maluku Utara yang dimunculkan dengan klausa "Christianity through northen Maluku".

Dari Penjelasan di atas tergambar strategi wacana identifikasi yang digunakan oleh redaksi Jakarta post dalam menempatkan agama kristen pada posisi marginal. Makna yang muncul akibat identifikasi tersebut ialah Agama Kristen sebagai aktor yang pasif, dan objek penyaluran hasrat keserakahan bangsa Portugis. Pemilihan frasa "the first theology school in south Asia" menarik perhatian khalayak agar tertarik mengetahui kelengkapan berita. Walaupun pada isi berita tidak pernah diuraikan mengenai peristiwa konflik pembunuhan masyarakat sipil apakah benar-benar bernuansa syara atau tidak seperti yang ditonjolkan pada judul.

Dengan adanya identifikasi redaksi Jakarta post sangat subjektif menggunakan pengantar judul "roots of the north maluku conflict", maka judul tersebut dapat menyamarkan kekejian pembunuhan masyarakat sipil di Maluku Utara. Pengantar judul yang berupa frasa "roots of the north maluku conflict" tersebut memberikan makna dan kesan kekerasan pembunuhan itu terjadi bukan karena sifat amoral atau watak keji dari Agama Islam atau Kristen, melainkan karena desakan kebijakan pemerintah pusat dengan hadirnya PP 42/1999 tanpa mempertimbang status budaya dan batas-batas wilayah, sehingga konflik bergejolak sampai pada bernuansa syara atau agama.

Data (6):

They (Actor) abandoned (Material Process) at the height of the Christian-Muslim conflict (Attribute) in North Maluku (Goal). (Paragraph 9).

Tabel 6. Analisis Proses material data (6)

\section{They abandoned at the height of in North the Christian- Maluku Muslim conflict}

\section{Pt: Actor Pr:Material Pt:Attribute Pt:Goal}

Berdasarkan tabel 6, proses material dihadirkan dengan verba "abandoned". Dari analisis wacana yang dilakukan dapat pula diungkap motif surat kabar Jakarta Post menampilkan pelaku konflik itu adalah Kristen-Islam, seperti di munculkan dengan kalimat berikut "at the height of the Christian-Muslim conflict". Motif redaksi Jakarta Post pada wacana tersebut tergambar pada identifikasi yang subjektif dan bersifat negatif. Identifikasi di atas bertujuan agar gambaran konflik Kristen- Muslim yang sampai kepada khalayk ialah konflik yang menimpa banyak orang, serta merasa bersalah atas konflik itu terjadi.

Strategi wacana yang digunakan pada judul "roots of the north maluku conflict" ialah strategi wacana yang menampilkan kategori aktor sosial dalam pemberitaan. Umumnya, kategorisasi yang ditampilkan tersebut bukan merupakan tambahan informasi, melainkan dapat pula digunakan untuk mengetahui lebih jauh mengenai maksud adanya kategorisasi tersebut. Adapun kategorisasi yang digunakan oleh redaksi Jakarta Post pada wacana di atas ialah kategorisasi fisik.

Aktor yang melakukan kekerasan konflik di beri kategorisasi Kristen-Muslim, sedangkan korban kekerasan konflik di beri kategori masyarakat sipil di Maluku Utara. Dengan pilihan kata pada judul dan wacana di atas semakin menarik perhatian pembaca. Kategorisasi berupa Kristen-muslim pada wacana bermakna bahwa konflik itu bernuansa aroma agama atau syara. Di sisi lain, kategorisasi yang dilekatkan kepada korban konflik ialah masyarakat sipil di Maluku Utara, dapat bermakna sesuatu yang tidak wajar dilecehkan karena konflik itu mengandung pelanggaran hak asasi manusia. Dengan label yang diberikan oleh redaksi Jakarta Post kepada masingmasing aktor pada judul wacana berita dan konteks wacana berita ini, maka yang menempati posisi marginal ialah korban kekerasan konflik. 


\section{SIMPULAN}

Posisi masyarakat sipil Maluku utara, sesungguhnya masyarakat yang sangat menghargai perbedaan budaya, adat-istiadat dan agama. Praktik wacana yang digunakan oleh media Jakarta Post di dalam memberitakan peristiwa konflik di Maluku Utara pada wacana berita dengan judul "roots of the north maluku conflict" ialah secara eksplisit tidak terlalu terbuka karena hampir dari sembilan data yang ditemukan, terdapat dua paragrap saja yang secara jelas ditulis tentang konflik, yakni pada data (1) dan data (6), namun dari dua data itu aktornya berbeda, yakni di data (1) aktor yang dimunculkan ialah masyarakat sipil, pemerintah dan militer sedangkan pada data (6) aktor yang dihadirkan ialah agama kristen dan agama Islam. Secara keseluruhan proses ketransitifan yang ditemukan ialah 6 data proses material. Datanya dapat dilihat pada tabel berikut.

Tabel 10: Daftar proses ketransitifan yang ditemukan

\begin{tabular}{ll}
\hline Data () & Proses Material \\
\hline Data (1) & have begun, \\
Data (2) & against external values is, dan emerged \\
Data (3) & ruled dan existed \\
Data (4) & which was, dan tied \\
Data (5) & set out to spread, was established, dan backed \\
Data (6) & Abandoned \\
\hline
\end{tabular}

Bentuk praktik wacana yang digunakan dalam berita dengan judul "roots of the north maluku conflict" ialah peneliti menemukan terdapat dua bentuk, yakni bentuk identifikasi dan bentuk kategorisasi terhadap peristiwa konflik masyarakat sipil di Maluku Utara. Melalui dua bentuk itu konflik dapat diketahui bahwa konflik itu bermuara pada konflik antara Kristen vs Islam yang berawal dengan penerapan kebijakan pemerintah akibat hadirnya PP 42/1999 di Maluku Utara. Konflik itu mengalami gangguan mental cukup parah pada anak-anak dan masyarakat sipil sehingga peneliti perlu merekomendasikan; Pertama, agar terus dilakukannya rekonsoliasi dan pemulihan mental terhadap anak-anak. Kedua, perlunya melakukan revisi atas PP 42/1999 tentang tapal batas kecamatan di Maluku Utara sebagai sumber utama konflik di Maluku Utara.

\section{UCAPAN TERIMA KASIH}

Tim Peneliti mengucapkan terima kasih dan penghargaan kepada Eva Tuckyta SariSujatna(Dosen FIB UNPAD) yang telah membantu menyumbangkan pikiran dan gagasan kearah penyempurnaan penelitian dan penulisan ini.

\section{DAFTAR PUSTAKA}

Eriyanto. 2008. Analisis Wacana: Pengantar Analisis Teks Media. Yogyakarta: Lkis.

Eggins, Suzanne. 2004. An Introduction to Systemic Functional Linguistics, Second Edition. New York: Servis Filmsetting Ltd, Manchester.

Fairclough, Norman.1995.Media Discourse.Uniter Kingdom: Edward Arnold.

Gerot, Linda \& Wignell, Peter. 1994. Making Sense Of Functional Grammar. Australia: Gerd Stabler.

Halliday,M.A.K. and Matthiessen,Cristian. 2004. An Introduction to Functional Grammar (Third Edition).New York: Oxford University Press Inc.

Heriyanto. 2001. Pelangi Budaya. Bandung: UvUla Press Fakultas Sastra UNPAD.

Sujatna, Eva Tuckyta Sari. 2008. Tata Bahasa Funsional. Bandung: Uvula Press UNPAD.

Stefan,T et al. 2000. Methods of Text and Discourse Analysis. London: Sage Publication.

Sobur,Alex.2009. Analisis Teks Media:Suatu Pengantar untuk Analisis Wacana, Analisi Semiotik, dan Analisis Framing.Bandung: Remaja Rosdakarya.

Junling Wang "A Critical Discourse Analysis of Barack Obama's Speeches". Journal of Language Teaching and Research, Vol. 1, No.3, (May 2010) pp. 254261.

Subagyo, Ari. P. "Paduan Pragmatik Dengan Analisis Wacana Kritis". Jurnal Ilmian Masyarakat Linguistik Indonesia. Vol.28, No. 2, (Agustus 2010) htm, 177-187.

http://www.thejakartapost.com/news/2000/01/25/rootsnorth-maluku-conflict.html, (diakses tanggal 15 Juni 2013, pkl. 14.48 WIB). 